\title{
Follow-up on Family Practice Residents' Perspectives on Length and Content of Training
}

\author{
Marguerite Duane, MD, MHA, Susan M. Dovey, PhD, Lisa S. Klein, and \\ Larry A. Green, $M D$
}

Background: The structure of family practice residency programs remains essentially unchanged from the model first proposed more than 35 years ago. Advances in medical technology and knowledge combined with increasing restrictions on resident work hours and decreasing medical student interest invite reconsideration of how family physicians are trained.

Methods: We resurveyed 442 third-year family practice residents who had participated in a prior study in 2000 to determine whether their opinions about the length and content of residency had changed and whether they would still choose to be a physician and a family physician.

Results: Thirty-seven percent of responding third-year residents favored extending family practice residency to 4 years. Compared as groups, there was relatively little change in opinion between firstand third-year residents. However, residents' individual responses about the settings and content areas for which they would be willing to consider extending training varied considerably between years 1 and 3. Personal characteristics did not seem to influence residents' opinions about length and content of training. Reasons for favoring a 4-year program and barriers to change were similar to those reported previously. Residents' commitment to medicine and family medicine was still strong and was not associated with their opinions about length of training.

Conclusion: Although most surveyed residents favored a 3-year residency program, a substantial minority still supported extending training to 4 years, and the majority would still choose to enter family medicine programs if they were extended. Given a lack of consensus about specific content areas, family medicine should consider a period of experimentation to determine how to best prepare future family physicians. (J Am Board Fam Pract 2004;17:377-83.)

In the autumn of 2000, we conducted a survey of family practice program directors, first-year residents, and family physicians due for their first board recertifications to determine their opinions about the need to change the current structure of family medicine training programs. ${ }^{1}$ This survey was modeled in part after a survey used by Ferentz et $\mathrm{al}^{2}$ in 1988 , who asked program directors, thirdyear family medicine residents, and practicing family physicians whether they thought family medi-

Submitted, revised, 15 March 2004.

From the Robert Graham Center: Policy Studies in Family Medicine and Primary Care, Washington, DC. Address correspondence to Marguerite Duane, MD, c/o 1350 Connecticut Avenue, NW, Suite 950, Washington, DC 20036 (e-mail: lgreen@afp.org).

This study was funded by the American Academy of Family Physicians. The information and opinions contained in research from the Graham Center do not necessarily reflect the views or policy of the AAFP.

See Commentary on page 391. cine residency training should be 3 or 4 years. Like the findings from the Ferentz study, our results showed that most respondents supported the current 3-year model of training, but a substantial minority (almost one-third of all respondents) favored extending family practice residency to 4 years. Disagreement existed among the 3 groups about what changes needed to be made, but all identified a number of barriers that would make it difficult to change the current training model.

Despite advances in medicine and changes in the health care system, family practice residency programs are still largely modeled on recommendations from the 1966 Willard Report, ${ }^{3}$ implemented in 1969. Since our initial study 2 years ago, further changes have occurred that will affect the preparation of residents for the practice of family medicine. In their report on Resident Duty Hours published in June 2002, ${ }^{4}$ the Accreditation Council for Graduate Medical Education made recommendations to include limits on the number of hours residents may work per week, the frequency of in-house call, 
and the minimum rest period that should be provided between duty periods. Such recommendations will certainly impact the ability of residency programs to meet the multitude of requirements in family medicine training.

The continuing decline of US medical graduates choosing family practice is also likely to influence the future of family medicine residency training. In 2003, the percentage of US medical school seniors who matched in family practice decreased for the sixth year in a row, ${ }^{5}$ with only $42 \%$ of the 2940 family medicine positions offered filled by US seniors. A study sponsored by the American Academy of Family Physicians (AAFP) and conducted by the University of Arizona in 2000 identified numerous factors that discourage medical students' from pursuing family medicine, such as concerns about the breadth of knowledge required and the lack of perceived prestige of the specialty. ${ }^{6}$ In response to the decline in medical student interest and other concerns, national family medicine organizations have undertaken the Future of Family Medicine Project $^{7}$ to address the future direction of the specialty.

Because of such developments, it is relevant and timely to re-evaluate the opinions of residents in family medicine training programs. Therefore, for this study, we surveyed the same group of residents from the first study when they were well into their third year of residency (PGY3) to determine 1) the opinions of third-year family medicine residents graduating in 2003 about the length and content of residency; 2) whether their opinions had changed since their first year of residency and the direction of any change; 3 ) whether there are personal characteristics of residents that are associated with changes in opinion; and 4) whether residents nearing the completion of their residency would still choose to be a physician, a family physician, and choose the same residency program.

\section{Methods}

In our initial study, we surveyed all first-year residents from the 14 military family practice programs, as well as all first-year residents from a random selection of 116 of the 464 remaining residency programs. A total of 997 first year family practice residents were surveyed, representing ap- proximately one third of all first-year family medicine residents matriculating in the United States in the year 2000. Fifty-four percent of these residents (533 of 997) responded.

For this survey, we surveyed the same group of residents who participated in the initial study so we could perform a pair-wise comparison to determine whether their opinions changed during residency. Of the original 533 residents, 39 had left family practice residency training. Various reasons were given, including, but not limited to, changing specialties, leaving medicine, or serving as a general medical officer or flight surgeon, which represented the majority. Identifying information from the first survey could not be confirmed for 52 of the 494 remaining residents. These residents were also excluded from the second survey's analysis, leaving 442 potential respondents. A 2-page self-administered questionnaire developed for the first study was modified to include 3 additional questions. Questionnaires were mailed in November 2002. A second mailing was sent in January 2003. Follow-up fax transmissions and telephone calls were made in February 2003, and a total of 300 surveys were returned (response rate, 68\%). We were able to include 280 of the questionnaires received by February 20, 2003, in the analysis. The remaining 20 surveys had missing data or lacked the survey identification number necessary for pairwise comparisons.

The questionnaires included closed questions to collect demographic data, information on whether post-residency training was anticipated, and respondents' views on the optimal length of residency training. The questionnaire specifically asked whether change to a 4-year family practice program was favored and for an indication of willingness to complete a fourth year to receive more training in a variety of settings and subject areas. Open-ended questions asked respondents to list factors that would lead them to favor a change in length of training or continue with a 3 -year program and to list barriers they perceived to changing to a 4-year program. The additional questions in this survey asked residents if they would still choose medicine as a career, family medicine as a specialty, and the same residency program knowing what they know now. Data were entered into a computer database and analyzed at The Robert Graham Center in Washington DC. 


\begin{tabular}{|c|c|c|}
\hline Characteristic & $\begin{array}{l}\text { Responders } \\
(\mathrm{N}=280)\end{array}$ & $\begin{array}{c}\text { Lost to Follow-up and } \\
\text { Nonresponders } \\
(\mathrm{N}=252)\end{array}$ \\
\hline \multicolumn{3}{|l|}{ Demography } \\
\hline Mean age & 30.3 years & 30.7 years \\
\hline Sex (\% male) & 40.7 & 41.3 \\
\hline \multicolumn{3}{|l|}{ Total outstanding educational loan amount (\%) } \\
\hline$<\$ 25,000$ & 22.8 & 28.4 \\
\hline$\$ 25,000-\$ 100,000$ & 35.3 & 36.0 \\
\hline$\geq \$ 100,000$ & 41.9 & 35.6 \\
\hline \multicolumn{3}{|l|}{ Residency characteristics } \\
\hline Setting & 49.8 & 48.6 \\
\hline Urban $(\%)$ & & \\
\hline Suburban (\%) & 39.6 & 40.6 \\
\hline \multirow{2}{*}{\multicolumn{3}{|c|}{ Type }} \\
\hline & & \\
\hline Community based-NOT affiliated with a medical school (\%) & 22.3 & 21.5 \\
\hline Community-based, affiliated with a medical school (\%) & 45.0 & 40.2 \\
\hline Community based, administered by a medical school (\%) & 9.0 & 7.2 \\
\hline University based (\%) & 17.6 & 17.1 \\
\hline Military program $(\%)(P<.001)$ & 6.1 & 13.9 \\
\hline Future plans - Planned post-residency training (\%) & 23.2 & 21.8 \\
\hline Optimal family practice residency length is 3 years & 69.6 & 79.2 \\
\hline \multicolumn{3}{|l|}{ Would have chosen family medicine if residency length was: } \\
\hline 2 years & 48.7 & 56.1 \\
\hline 3 years & 100.0 & 100.0 \\
\hline 4 years & 68.7 & 65.0 \\
\hline$\geq 5$ years $(P=.014)$ & 7.8 & 2.9 \\
\hline Favor a change to a 4 year residency $(P=.031)$ & 36.5 & 27.5 \\
\hline
\end{tabular}

\section{Data Analysis}

The analytic plan was first to assess differences between responders and nonresponders to the 2002 survey, then to compare overall responses from the 2 surveys, and finally to directly measure changes by pairing responses of third-year residents with answers they provided to the same questions in their first residency year. In addition, we describe the third-year residents' views on their future prospects and relate these to their opinions about residency length and content.

Overall differences between the 2 surveys were tested using the $\chi^{2}$ test of differences in proportions. Differences between responders and nonresponders in the follow-up survey were assessed with reference to demographic characteristics using the nonparametric Wilcoxon-signed-rank test. Because of multiple testing, $P<.01$ was the level of significance set for this study.

Content analysis of free text responses determined the themes of residents' responses to questions relating to what they perceived as important factors supporting changed residency length and continuation of current 3 -year programs and their views on a medical career now that they had almost finished training.

\section{Results}

Of the 533 resident respondents to the 2000 survey, 280 returned follow-up surveys in 2002 sufficient for analysis. Apart from a higher proportion of residents being in military programs at baseline (13.9\% versus $6.1 \% ; P=.003)$, responders to the second survey were similar to responders to the first survey for whom a second response was not obtained with respect to age, sex, residency characteristics, and future plans, as shown in Table 1. Responders to the second survey were more likely to have indicated support for longer residencies in the first survey, as also seen in Table 1 . They were also, in general, more willing to extend training in more content areas.

\section{Length of Training}

When asked about the optimal length of residency, most respondents still favored a 3-year residency program $(69.7 \%$ in 2000 and $65.2 \%$ in 2002). The majority of respondents $(196 ; 74.2 \%)$ did not change their view on the optimal length of residency. Of the 68 PGY3 residents who did change their view, $39(57.4 \%)$ favored a longer program length and 29 (42.6\%) favored a shorter program than they had elected earlier. 
When asked if they would have chosen a family medicine residency if it were a 2-year training program, only $39.9 \%$ of respondents said "yes," whereas $60.1 \%$ said "no." Again, the majority (188, $74.3 \%$ ) provided the same response in both study years. Of the 65 residents who changed their responses, two thirds who said "yes" at baseline now said "no" they would not choose a family medicine residency program if it were 2 years, and one third who initially said "no" now said "yes." When asked whether they would have chosen a family medicine residency if it were a 4-year training program, 63.2\% said "yes" and 36.8\% said "no." Again, a majority $(72.9 \%)$ maintained the same response in both years. Of the 72 who changed their response, more than half $(43,59.7 \%)$ now said "no," they would not choose a 4-year program.

When asked directly whether they would favor a change in residency length to 4 years, $62.9 \%$ of respondents said "no" and 37.1\% said "yes"; more than half of the respondents $(51.8 \%)$ replied negatively in both surveys, and $26.5 \%$ of respondents replied affirmatively in both surveys.

Third-year residents listed factors supporting change to a 4-year residency that were similar to those they had provided in their first year. The broad scope of family medicine was again seen as an adequate justification for extending residency training for many ("so much to learn, so little time"). This consideration became particularly pertinent when family medicine training was compared with training in other medical specialties: "How can med-peds program training be 4 years and FP training, which covers adults, peds, and $\mathrm{OB}$ medicine, only be 3 years? Our specialty needs to be better trained." More exposure to procedures and specialty training continued to be seen as a major advantage of a 4-year program. A new factor in support of extended residency was the effect of new regulations limiting residents' working hours: "With decreasing hours of work, we are cutting our learning opportunities by $15 \%$ to $20 \%$. There is too much info to learn in FP to allow competent physician training in less than 4 years."

Third-year residents listed factors supporting continued 3-year residencies that were similar to those they had provided in their first year. Many thought 3 years was adequate to prepare them for caring for patients; although they appreciated that there is a lot they do not know, they anticipated continuing to learn throughout their careers. A yearning to be free of the constraints of formal education and the unhealthy work environment of residency was evident: "No one should work this hard for more than 3 years. The pay really is inadequate"; "Why prolong the torture?"; "I'm so ready to be done! There will always be more to learn. ..." Both longer and shorter training periods were considered unattractive for reasons of relativity with other specialties' programs, financial reasons, and simply because change is harder than "inertia."

When asked to list the single greatest barrier to a 4-year residency, most cited the time commitment of an extra year and related funding issues. Financial barriers included doubt about the availability of federal funding for a fourth year, their institutions' reluctance to fund fourth-year positions, residents' (in)tolerance of continued low salaries (often in the face of large student loans and the need for loan repayment), and the perception that even after completing a 4-year residency, their income as practicing family physicians would be relatively low compared with that of other medical specialties. Some respondents referred to burnout, fatigue, poor working conditions, and inefficient or inadequate educational components of their current 3-year programs and identified those as major barriers to the success of 4-year programs if it would be more of the same: "Unless restructured, doubt that it [the 4th year] would add much to our education"; "It is not necessary to extend length. The quality of residency programs needs to be improved."

\section{Setting and Content of Training in a 4-Year Program}

When analyzed as groups, there was little change between first- and third-year residents in the percentage of residents definitely willing to complete a fourth year of training for training in the various settings (Table 2). There was a consistent decrease in the percentage of residents definitely willing to complete a fourth year of training in the listed content areas, except for teaching, leadership training, and practice management, which increased.

Although there were relatively small changes in group percentages, as seen in Table 2, the residents' individual responses regarding their willingness to consider extending training varied considerably between years 1 and 3 . For all settings except hospitals, nursing homes, and home care and in all 
Table 2. Percentage of Residents at PGY1 and PGY3 Definitely Willing to Complete a Fourth Residency Year If It Involved More Training in the Following Settings and Content Areas

\begin{tabular}{|c|c|c|}
\hline & $\begin{array}{c}\text { PGY1 } \\
(\%)\end{array}$ & $\begin{array}{c}\text { PGY3 } \\
(\%)\end{array}$ \\
\hline \multicolumn{3}{|l|}{ Setting } \\
\hline Hospital & 15.8 & 15.8 \\
\hline Model FP unit & 12.6 & 14.4 \\
\hline Private practice & 19.3 & 17.2 \\
\hline Community health center & 14.7 & 13.3 \\
\hline Nursing home & 4.2 & 5.6 \\
\hline Home care & 3.9 & 3.2 \\
\hline Subspecialty office & 16.1 & 18.6 \\
\hline Ambulatory surgery & 16.8 & 19.6 \\
\hline \multicolumn{3}{|l|}{ Content areas } \\
\hline Mental health & 12.3 & 10.2 \\
\hline Adult medicine & 20.0 & 16.1 \\
\hline Maternity care & 27.7 & 18.6 \\
\hline Women's health & 29.1 & 24.2 \\
\hline Adolescent medicine & 24.2 & 23.2 \\
\hline Children & 31.6 & 24.2 \\
\hline Older patient care & 16.5 & 15.1 \\
\hline General surgery & 10.9 & 7.0 \\
\hline Genitourinary & 11.2 & 9.1 \\
\hline Eye disorders & 13.0 & 9.5 \\
\hline Otolaryngology training & 14.7 & 10.9 \\
\hline Musculoskeletal medicine & 23.9 & 22.5 \\
\hline Sports medicine & 29.1 & 23.9 \\
\hline Skin conditions & 26.0 & 21.4 \\
\hline Emergency care & 27.0 & 26.0 \\
\hline Office procedures & 40.7 & 36.8 \\
\hline Community medicine & 16.1 & 10.2 \\
\hline Health promotion & 20.7 & 11.2 \\
\hline Information systems & 9.5 & 8.4 \\
\hline Practice management & 13.9 & 17.9 \\
\hline Teaching & 13.3 & 13.7 \\
\hline Research & 8.4 & 5.3 \\
\hline Leadership training & 9.5 & 13.0 \\
\hline
\end{tabular}

content areas except general surgery and research, less than half of the respondents provided exactly the same reply in their PGY3 and PGY1 years. When residents changed their responses, more changed their responses toward being less willing to extend residency to gain further training in the various settings and content areas, with the exception of hospital training. For respondents who replied "definitely" in both surveys, the percentage of those indicating that they were not willing to extend residency for further training usually was higher than the percentage of residents indicating they definitely were willing to have more training, except for women's health, children's health, sports medicine, skin conditions, emergency medicine, and office procedures.

\section{Comparison of Views According to Personal Characteristics of Residents}

Residents were grouped according to whether the majority of their responses in PGY3 indicated less willingness than in PGY1 to extend residency for training in the listed areas $(90,31.6 \%)$, more willingness $(47,16.5 \%)$, or most of their responses were the same in the 2 surveys (140, 49.1\%). There was no difference among these groups in terms of age, sex, marital or parent status, residency setting or type, or the amount of educational loans they carried at either PGY1 or PGY3. Respondents who were consistently opposed to a 4-year residency ( $\mathrm{N}=125,45 \%$ of respondents) were no different from other residents in terms of their demographics, residency, or indebtedness.

\section{Family Medicine Residents' Commitment to Medicine}

Most respondents $(81.8 \%)$ indicated that, having nearly reached the end of their medical training, they would still choose a medical career, still choose specialization in family medicine $(82.1 \%)$, and still choose to train in their current residency program (82.8\%). Length of residency did not seem to be a factor in respondents' contentment with their career choice. The majority $(59.3 \%)$ of the 27 PGY3 residents who would not still choose to be a physician replied that they would still have chosen a family medicine residency if it were a 4-year program. Similarly, even if they would not again choose to be family physicians $(\mathrm{N}=34)$ or not again choose their current residency programs $(\mathrm{N}=33)$, a 4-year residency program would not have been the deciding factor for most $(64.7 \%$ and $72.7 \%$, respectively). There was no statistically significant difference between those who would and would not still choose a career in family medicine in terms of age, sex, marital status, indebtedness, residency type, or location.

Although most comments positively endorsed the PGY3 respondents' choice of medicine, family medicine, and their current residency programs, reasons given for not still choosing to be a physician centered around financial concerns ("I might be a teacher as their pay has so dramatically increased with a much better lifestyle"), the regulatory environment, with a particular emphasis on concerns about litigation, the work environment ("too much business, not enough time with patients"), and lifestyle issues. Similar reasons were given for having second thoughts about family medicine as their specialty choice: "a great deal of sacrifices-personal financial debt, malpractice, privatization of medicine." Other medical special- 
ties that now appealed to residents included internal medicine, pediatrics, emergency medicine, orthopedics, dermatology, and psychiatry. The big advantages of family medicine were seen as its breadth, flexibility, and diversity.

\section{Discussion}

Slightly more than one third of responding thirdyear family medicine residents favored a change to a 4-year family medicine residency. This proportion seems to be stable over a period of some 15 years and did not change for first-year residents when resurveyed as third-year residents. ${ }^{1,2}$ The proportion of surveyed family medicine residents who stated they would choose family medicine residency training if it were 4 years long was similarly stable at about $65 \%$, whereas, only $39 \%$ of residents would still choose family medicine if it were a 2-year program. Personal characteristics, such as age, sex, indebtedness, and having children, do not seem to strongly influence residents' views about the length and content of training. These data do not support Zweifler's ${ }^{8}$ conclusion that a reduction in training time or debt load would increase medical student interest in family medicine.

Within this stability of the group is substantial individual variation of resident opinion about what should be changed about the settings and content of their training if it were extended to 4 years. This variation probably derives from differences in medical school and residency experiences intersecting with variation in the needs and demands of the patient populations that residents aspire to serve. As would be expected, residents' willingness to extend training in various areas generally declined as they proceeded through residency into their third year of training. By examining definite opinions held by residents, areas where there may be more resident support than resistance can be nominated (eg, office procedures, practice management, child health, women's health, skin conditions, sports medicine, and emergency medicine). Areas for which there might be more resistance include more training in hospitals, nursing homes, home care, and subspecialty offices and in general surgery and research.

Residents' reasons for supporting a 4-year residency program in this survey were similar to those that they provided when they were first-year residents. The broad scope of family medicine, the need for more training in specific clinical areas, and comparison with the training received by other medical specialists, in their opinion, might warrant an additional year. An additional reason offered relates to new regulations of resident work hours that are expected to impact the residents' abilities to learn as much medicine given the decreased amount of time they will be allowed to work. Again, third-year residents identified financial barriers (low resident salaries, lower salaries of practicing family physicians) coupled with the time commitment of an additional year as the greatest barriers to a 4-year residency.

Most residents' commitment to medicine and to family medicine was still strong in their third year of training. More than $80 \%$ of the respondents would still choose medicine and the specialty of family medicine as a career. The length of the training program did not seem to influence their opinions whether they were in their first or third year of training. The reasons residents would not choose medicine or family medicine related to the poor reimbursement for the level of work, especially in light of their loans; lifestyle issues; and the level of bureaucracy built into the health care system. These are similar to reasons given by students surveyed in a recent study conducted at the University of Arizona. ${ }^{6}$ Neither the Arizona study nor this study provides evidence that extending the length of training would exacerbate these concerns.

It is unusual to be able to conduct a follow-up study of young professionals during a time of great life changes, using a standardized study instrument. Although it is a strength of this study that we were able to pair responses to the same questions over a time interval of more than 2 years, a weakness is that we do not know if the sample sizes for the paired comparison were adequate to clearly define differences in responses. We could include in this analysis only 280 surveys of the initial group of 533 first-year family medicine residents. These 533 residents may themselves have been a biased respondent group because they chose to respond to the initial survey, whereas 464 others did not. If these data are biased, the biases probably work in the direction of their representing the opinions of residents with greater interest in training issues and further development of their profession.

Two implications for policy emerge from this analysis: first, if a decision were made to restructure residency programs that required them to be 4 
years long instead of 3 , it would be likely to result in attracting some students and repelling others, with the net effect on student interest being relatively small. Of greater threat to family medicine residencies are poorly organized programs, curricula inhibited by uncommitted leadership and inadequate educational components, and inertia when action is needed.

Second, if a period of active experimentation could be launched, particular consideration should be given to longer training programs with greater emphasis placed on selected content areas, concordant with limitations on duty hours, and matched to anticipate new models of family practice. Consideration should be given to recommendations from the Future of Family Medicine Project ${ }^{7}$ and the principles articulated in the Institute of Medicine's report, Crossing the Quality Chasm, ${ }^{9}$ as new partnerships are explored. Of particular interest is potential collaboration with general internal medicine, a primary care discipline concurrently reconsidering its own residency programs. ${ }^{10}$

\section{Conclusion}

Although most family medicine residents are satisfied with their career choice and support the current 3-year model of training, across a decade and a half, a substantial minority have favored a 4-year training program. Given contemporary concerns about resident work hours and the adequacy of medical education for new models of practice that are needed to enhance care for all Americans, an opportunity for experimentation is at hand. Some family medicine residencies should proceed to elaborate new approaches, confident that there is support for targeted change among family medicine residents as they enter and depart residency training.

\section{References}

1. Duane M, Green LA, Dovey S, Lai S, Graham R, Fryer GE. Length and content of family practice residency training. J Am Board Fam Pract 2002;15: 201-8.

2. Ferentz KS, Sobal J, Colgan R. Family medicine residency training-three or four years? J Fam Pract 1988;26:415-20.

3. Meeting the challenge of family practice. Report of the Ad Hoc Committee for Family Practice of the Council on Medical Education. Chicago: American Medical Association; 1966.

4. Accreditation Council for Graduate Medical Education. Report of the ACGME work group on resident duty hours [monograph on the Internet]. Chicago: Accreditation Council for Graduate Medical Education; 2002 [cited 2003 Sep 15]. Available from: http://www.acgme.org/DutyHours/ wkgroupreport611.pdf.

5. American Academy of Family Physicians Division of Medical Education. 2004 National Match Results and Information. Leawood (KS): American Academy of Family Physicians [cited 2004 Aug 6]. Available from: http://www.aafp.org/match/table01.htm.

6. Campos-Outcalt D, Senf J, Kutob R. Comments heard by US medical students about family practice. Fam Med 2003;35:573-8.

7. Future of Family Medicine. Family Practice Working Party, Organization of Academic Family Medicine. Ann Fam Med; 2 Suppl 1.

8. Zweifler J. Why we should reduce family practice training to two years. Acad Med 2003;78:885-7.

9. Institute of Medicine. Crossing the quality chasm: A new health system for the 21 st century. Washington DC: National Academy Press; 2001.

10. Task Force on the Future of General Internal Medicine. Future of General Internal Medicine: report and recommendations. Washington DC: Society of General Internal Medicine; 2003. 